\title{
Erratum
}

\section{Erratum to "Theory and practice of myofascial pain as both practicing clinician and patient" (a Physician Commentary)}

\author{
[J. Back Musculoskeletal Rehabil. 8 (1997) 173]
}

\section{Mark Starr}

The publisher regrets that an important word was inadvertently omitted from the above paper. The sentence beginning nineteen lines down from

\footnotetext{
${ }^{1}$ PII of original article: S1053-8127(96)00248-O
}

the second column on p. 173 should read:

"It was always a cause for consternation when the patient did not improve after a trial of NSAIDS, modalities, excercises, or the occasional "Travelltype' trigger point injections." 